\title{
ESTADO ACTUAL DE LOS RECURSOS GENÉTICOS DE Phaseolus coccineus (Fabaceae) en México
}

\author{
Current status of the genetic Resources of Phaseolus coccineus \\ (FAbaceae) in Mexico
}

\author{
Régulo Ruíz-Salazar ${ }^{1,2 *}\left(\mathbb{D}\right.$, Sanjuana Hernández-Delgado ${ }^{2}(\mathbb{D})$, María Luisa \\ Patricia Vargas-Vázquez ${ }^{3}$ (D) y Netzahualcoyotl Mayek-Pérez ${ }^{1,4}$ (D)
}

\begin{abstract}
1. Centro de Biotecnología Genómica - Instituto Politécnico Nacional, Boulevard del Maestro Esq. Elias Piña S/N, Col. Narciso Mendoza, CP. 88710, Reynosa, Tamaulipas, México.

2. Unidad Académica Multidisciplinaria Reynosa Aztlán, Universidad Autónoma de Tamaulipas, Calle 16 y Lago de Chapala S/N, CP. 88740, Reynosa, Tamaulipas, México.

3. Campo Experimental Valle de México-INIFAP. Carretera Los Reyes-Texcoco km 13.5. Coatlinchán, Texcoco, México. AP. 307. CP. 56250.

4. Unidad Académica Multidisciplinaria Reynosa Rodhe,Universidad Autónoma de Tamaulipas, Carretera Reynosa - San Fernando, cruce con Canal Rodhe Col. Arcoiris, C.P. 88779, Reynosa, Tamaulipas, México.
\end{abstract}

*regulo.ruiz@docentes.uat.edu.mx

Citar este artículo RUÍZ-SALAZAR, R., S. HERNÁNDEZDELGADO, M. L. P. VARGASVÁZQUEZ \& N. MAYEK-PÉREZ. 2021. Estado actual de los recursos genéticos de Phaseolus coccineus (Fabaceae) en México. Bol. Soc. Argent. Bot. 56: 289-305.

DOI: https://doi. org/10.31055/1851.2372.v56. n3.32297

Recibido: 19 Feb 2021

Aceptado: 29 Jun 2021

Publicado impreso: 30 Set 2021

Editora: Viviana Solis Neffa (D)

ISSN versión impresa 0373-580X ISSN versión on-line 1851-2372

\section{Summary}

Background and aims: The ayocote bean (Phaseolus coccineus L.; $2 n=2 x=22$ ), is a species native from Mexico that has been domesticated for human consumption, however there is little few information about its qualities, so the aim of this work consisted in investigating and gathering the most relevant aspects including: its center of origin and domestication, geographical distribution, patterns of morphoagronomic and genetic diversity, productivity, further of beneficial properties of its consumption, it should be noted that its distribution in America ranges from the South from the United States to Northern Argentina.

M\&M: Different sources of information, both printed and digital, were consulted, which included: libraries, internet databases, manuals and technical reports, as well as personal interviews with experts and producers.

Results: The results indicate the current situation of the genetic resource of the ayocote bean both in Mexico and in the world, which includes the different uses that the species has been given, for example its study in areas as diverse as forage production, bioremediation of soils, resistance to low temperatures, until introgression with other Phaseolus species.

Conclusions: Due to the various interesting characteristics that the ayocote bean has, it is suggested to develop studies aimed at characterizing genetically and morphoagronomically a greater number of populations of the species, with the aim of generating improved varieties of common bean according to their production areas from germplasm of $P$. coccineus.

\section{KEY WORDS}

Bean breeding, genetic diversity, phylogeny, molecular markers, tolerance to adverse factors.

\section{RESUMEN}

Introducción y Objetivos: El frijol ayocote (Phaseolus coccineus L.; $2 n=2 x=22$ ), es una especie originaria de México domesticada para consumo de su semilla, sin embargo existe poca difusión sobre sus cualidades, por lo que el objetivo del presente trabajo consistió en investigar y reunir sus aspectos más relevantes incluyendo: su centro de origen y domesticación, distribución geográfica, patrones de diversidad morfo-agronómica y genética, productividad, además de sus propiedades benéficas de consumo. Cabe destacar que su distribución en América abarca desde el Sur de los Estados Unidos hasta el Norte de Argentina.

M\&M: Se consultaron diversas fuentes de información tanto impresas como digitales, las cuales incluyeron: bibliotecas, bases de datos en internet, manuales y reportes técnicos, además de entrevistas personales con expertos y productores.

Resultados: Indican la situación actual del recurso genético del frijol ayocote tanto en México como en el mundo, donde se incluyen los distintos usos dados a la especie por ejemplo su estudio en áreas tan diversas como producción de forrajes, biorremediación de suelos, resistencia a bajas temperaturas, hasta la introgresión con otras especies del mismo género.

Conclusiones: Debido a las diversas características interesantes que tiene el frijol ayocote se sugiere desarrollar trabajos encaminados a caracterizar genética y morfoagronómicamente un mayor número de poblaciones de la especie, con el objetivo de generar variedades mejoradas de frijol común de acuerdo a sus zonas de producción a partir de germoplasma de $P$. coccineus.

\section{Palabras clave}

Diversidad genética, filogenia, marcadores moleculares, mejoramiento en frijol, tolerancia a factores abióticos. 


\section{INTRODUCCIÓN}

El frijol (Phaseolus spp.) es uno de los cultivos más importantes del sector agrícola en México, en 2019 se cultivaron 1.181 .669 ha, el rendimiento total fue $577.592 \mathrm{t}$, sin embargo, los rendimientos unitarios nacionales $\left(1,237 \mathrm{t} \mathrm{ha}^{-1}\right)$ aún se consideran bajos (SIAP, 2020). Los factores que han afectado la producción nacional de frijol son diversos, cabe mencionar que más del $85 \%$ de la superficie total se cultiva en condiciones de temporal o secano, con régimen de lluvias generalmente pobre e irregular, prolongados periodos de sequía, alta incidencia de plagas insectiles y enfermedades, ocurrencia de heladas tempranas o tardías, y uso escaso de insumos agrícolas, causas que dificultan la producción de este importante grano.

En la actualidad, existen cinco especies de frijol domesticadas y cultivadas en México: $P$. vulgaris L. 'frijol común', $P$. coccineus 'frijol ayocote', $P$. lunatus L. 'frijol lima', P. acutifolius Gray 'frijol tépari', $P$. polyanthus Greenman (sin. $P$. dumosus MacFady) 'frijol botil'. El frijol ayocote no está considerado en las estadísticas oficiales debido a que la superficie sembrada y la producción total de esta especie se incluye en las cifras del frijol común (Vargas-Vázquez et al., 2012), a pesar de considerarse la segunda especie de Phaseolus de importancia económica en México (Bellón et al., 2003). Lo anterior en parte se debe a las preferencias específicas de consumo del frijol, lo cual depende principalmente del color o tipo de grano, más que a la especie o algún atributo morfológico específico, aunado al desconocimiento parcial de los tipos de frijol producidos o disponibles en cada región de México, por ejemplo, en el norte del país el frijol se consume principalmente empacado o industrializado $(76 \%)$ mientras que en el sur se prefiere adquirirlo 'a granel' (77\%). Los frijoles ayocotes son preferidos en las grandes ciudades del centro del país, donde se concentra al menos un tercio de la población nacional, muchos de ellos migrantes de los estados donde se cultiva, principalmente Puebla y Veracruz (Vargas-Vázquez et al., 2012). Cabe mencionar que, aunque $P$. coccineus presenta un mayor tamaño de semilla con respecto a $P$. vulgaris, no se encontró una alta correlación entre sus características físicas y el tiempo de cocción. Además, el contenido nutricional y no nutricional es diferente en cada variedad, $P$. coccineus presenta un alto contenido de saponinas, las cuales se sabe son poderosos antioxidantes que protegen las células contra los radicales libres (Corzo-Ríos et al., 2020). En las regiones donde se cultiva el frijol ayocote, su uso está muy focalizado y frecuentemente, es para consumo familiar, y como máximo, se oferta en mercados ambulantes o 'tianguis' (Monroy \& Quezada, 2010; Rodríguez-Licea et al., 2010). El grano de frijol ayocote presenta distintos tamaños, formas y colores (Fig. 1).

El consumo per cápita anual de frijol en México se redujo de 22 a $9,9 \mathrm{~kg}$ en las últimas décadas (Reyes-Rivas et al., 2008; Rodríguez-Licea et al., 2010; SAGARPA, 2017) debido a cambios en los hábitos alimenticios de la población, migración del campo a las ciudades y en menor medida al mejoramiento de la economía familiar (ReyesRivas et al., 2008). A pesar de lo anterior, el frijol es una fuente importante de proteínas, minerales y vitaminas en la dieta de los mexicanos con escasos recursos, quienes representan alrededor de la mitad de la población. Una solución esencial en la producción de frijol en México, dada la escasa perspectiva del uso de tecnología por su baja rentabilidad, es la siembra de germoplasma mejorado. En este sentido, el mejoramiento genético del frijol común (P. vulgaris) ha sido consistente desde mediados del siglo XX. En la actualidad, existen numerosas variedades generadas, cultivadas y adaptadas a la compleja diversidad agroclimática del país. El impacto de este mejoramiento es importante si consideramos el factor riego, debido a que este incrementa al doble el rendimiento de grano comparado con los cultivos en condiciones de temporal (Acosta-Gallegos et al., 1996).

El frijol ayocote se cultiva, principalmente, en zonas marginales del Altiplano y Valles Altos de México (Vargas-Vázquez et al., 2007). VargasVázquez et al. (2007, 2012) señalan que el frijol ayocote se siembra como planta anual en monocultivo de temporal e intercalado con maíz. Las plantas que se intercalan con maíz pueden ser de guías cortas (en climas subhúmedos con lluvias en verano y con heladas durante el invierno), o plantas trepadoras que maduran después que el maíz (en climas calientes y subhúmedos con lluvias en verano y en áreas libres de heladas). Como planta bianual, el ayocote se siembra en el primer año asociado con maíz o con árboles 


\section{R. Ruíz-Salazar et al. - El frijol ayocote: recurso genético de México}
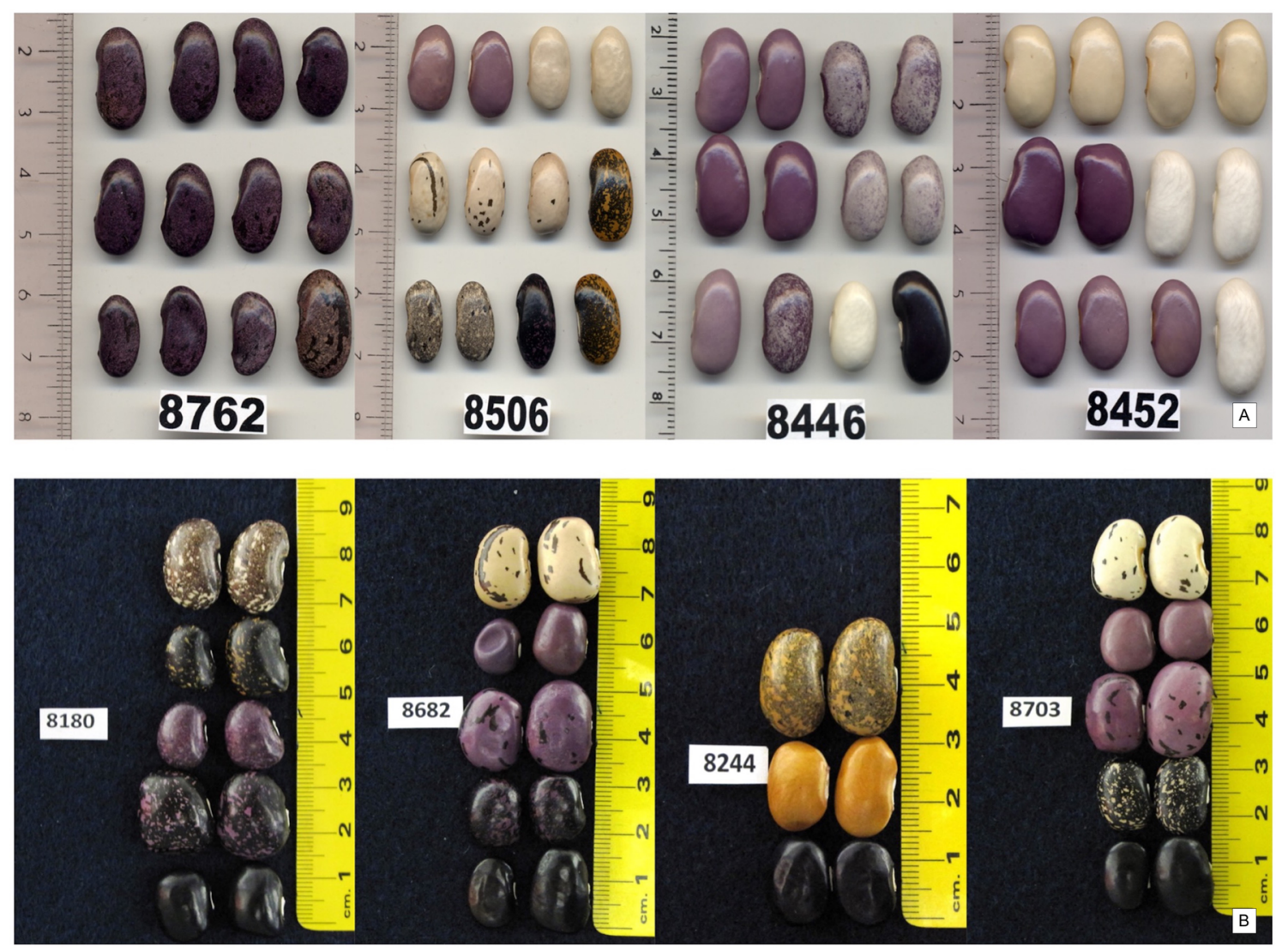

Fig. 1. Patrón de moteado y distintos colores de testa en semilla de frijol ayocote de los estados de Puebla (a) y Veracruz (b), los números corresponden al código de accesión asignado en la colección nacional de frijol ayocote, la cual está integrada por 798 colectas, y se encuentran bajo resguardo del Instituto Nacional de Investigaciones Forestales, Agrícolas y Pecuarias (INIFAP - Valle de México).

frutales y en el segundo como monocultivo o de nuevo asociado con maíz, aunque también puede encontrarse en los cercos y límites de las parcelas agrícolas, como planta semi-perenne o perenne. El monocultivo en el estado de Puebla es una práctica común, al igual que en regiones de los estados de Chihuahua, Durango y Zacatecas; mientras que, en Hidalgo, Estado de México, Chiapas y Tlaxcala se siembra asociado. Las variaciones en áreas cultivadas se asocian con la demanda del grano, los usos culinarios y las épocas de consumo (VargasVázquez et al., 2007).

La especie $P$. coccineus se divide, con base en información morfológica y de isoenzimas, en las siguientes subespecies y variedades: subsp. coccineus (variedades argenteus, coccineus, condensatus, griseus, lineatibracteolatus, parvibracteolatus, pubescens, semperbracteolatus, splendens, strigillosus, tridentatus y zongolicensis); subsp. striatus (Bradeng.) Freytag (variedades guatemalensis, minuticicatricatus, pringlei, purpurascens, rigidicaulis, striatus, timilpanensis); así como las subespecies darwinianus Hern.-Xol. \& S. Miranda, formosus (Kunth) Maréchal, Mascherpa \& Stainier, griseus (Piper) Freytag, obvallatus (Schltdl.) Maréchal, Mascherpa \& Stainier y polyanthus (Greenm.) Maréchal, Mascherpa \& Stainier, de las cuales no se identificaron variedades (Piñero \& Eguiarte, 1988; Freytag \& Debouck, 2002). De acuerdo con Vargas-Vázquez et al. (2007, 2012), P. coccineus subsp. coccineus es la que muestra mayor dispersión en el territorio mexicano; mientras que Delgado-Salinas (1988) indica que P. coccineus subsp. griseus se circunscribe a las 
sierras Madre Occidental y del Sur y $P$. coccineus subsp. glabellus se localiza particularmente en la sierra Madre Oriental de México.

La variabilidad genética de los diferentes tipos y especies de Phaseolus se está perdiendo debido a distintos factores, entre los que destaca la modernización de la agricultura, que tiende al monocultivo de variedades mejoradas encaminadas a satisfacer la demanda específica del consumidor por productos uniformes; los cambios de uso de suelo agrícola por cultivos más rentables o bien, el abandono de la tierra cultivable derivado de la migración a las grandes ciudades o al extranjero (Delgado-Salinas, 1988; Vargas-Vázquez et al., 2007, 2012).

Los objetivos del presente trabajo son actualizar y analizar el conocimiento científico relativo a $P$. coccineus, principalmente su origen, diversidad genética y rango de adaptación. Dicho conocimiento será de utilidad para la elaboración de estrategias de conservación y manejo de este importante recurso fitogenético en México.

\section{Materiales y Métodos}

Para la elaboración del presente trabajo, se consultaron diversas fuentes de información las cuales incluyeron: bibliotecas, bases de datos en internet las cuales incluyeron Scopus (www. scopus.com), Agris-FAO (www.fao.org/agris), USDA (www.usda.gov), Elsevier (www.elsevier. com), WoS Journal (www.wos-journal.com), Wiley Online Library (www.onlinelibrary.wiley. com), Taylor \& Francis Online (www.tandfonline. com), CONRICyT (www.conricyt.mx), PMC y ScienceDirect (www.elsevier.com), además de consultas personales con expertos y productores, manuales y reportes técnicos, de donde se tomaron los aspectos más relevantes del estado actual de P. coccineus.

\section{Resultados}

Origen, diversificación y adaptación de P. coccineus en México

En México, se domesticaron más de 100 especies importantes en la agricultura, entre ellas las pertenecientes al género Phaseolus (Delgado,
1985). Este género cuenta con al menos 77 especies confirmadas (D. Debouck, 2015. CIAT. Cali, Colombia. Comunicación personal), la mayoría de ellas silvestres. El género Phaseolus tiene su centro de origen en el centro-sur de México y parte de Centroamérica, en la región denominada Mesoamérica (Kaplan, 1980; Schmit \& Debouck, 1991; Llaca et al., 1994; Santalla etal., 2004; Delgado et al., 2006; Bitocchi et al., 2012; HernándezLópez et al., 2013) aunque persiste controversia al respecto. La especie $P$. coccineus sólo se observó en excavaciones en Norteamérica, en este sentido Kaplan \& MacNeish (1960) reportaron restos de ayocotes en una localidad de Ocampo, Tamaulipas con antigüedad estimada entre 9.000 y 7.500 años, también se encontraron evidencias arqueológicas de $P$. coccineus en una cueva de Tehuacán, Puebla con antigüedad estimada de 4.200 años (Kaplan, 1967) y en el Río Zape, Durango, con 3.300 años de antigüedad (Kaplan, 1965).

Según Delgado-Salinas (1988), el centro de origen de $P$. coccineus se concentra en las montañas de los estados de Puebla, Oaxaca y Chiapas, México. Las evidencias lingüísticas, arqueológicas y geográficas sugieren que el frijol ayocote se domesticó hace 7.000 a 9.000 años en las partes altas de México y de acuerdo con las rutas comerciales, los genotipos primitivos se dispersaron a Sudamérica posteriormente. En cuanto a su domesticación, Delgado-Salinas (1988) afirma que $P$. coccineus subsp. coccineus se obtuvo directamente de una planta silvestre y propone como ancestro putativo a $P$. coccineus subsp. formosus. Por su parte Hernández-Xolocotzi et al. (1959), menciona que $P$. coccineus ssp. darwinianus se originó de la cruza entre $P$. vulgaris y $P$. coccineus, sin embargo, Maréchal et al. (1978) consideraron que no había evidencia para separar a $P$. coccineus ssp. darwinianus en otra especie y la clasificaron como subespecie polyanthus. Un estudio de Piñero \& Eguiarte (1988) demostró, con base en el análisis isoenzimático, que $P$. coccineus subsp. polyanthus no es un híbrido resultado de la cruza entre $P$. vulgaris y $P$. coccineus subsp. coccineus ni tampoco un taxón independiente, como se suponía anteriormente, sino que debía considerarse una variedad de la ssp. coccineus. Aún en la actualidad el origen de subespecies, variedades y formas híbridas en $P$. coccineus, es difícil de determinar, debido a la constante introgresión genética entre 


\section{R. Ruíz-Salazar et al. - El frijol ayocote: recurso genético de México}

poblaciones.

Delgado-Salinas (1988) menciona que la domesticación del frijol ayocote ocurrió a partir de una o más formas de $P$. coccineus y que, posteriormente, habrían ocurrido eventos de hibridación entre esos cultivares incipientes y las formas silvestres, produciendo una variedad de formas primitivas que podrían divergir morfológica y ecológicamente. Esta domesticación, paulatinamente originó los acervos genéticos de la especie. De acuerdo con las consideraciones de Harlan \& de Wet (1971), Delgado-Salinas (1988) propuso como acervo genético primario de $P$. coccineus a las subespecies cultivadas coccineus y darwinianus, así como las no cultivadas formosus, griseus y glabellus, todas capaces de hibridarse exitosamente con germoplasma de $P$. coccineus. Por su parte, el acervo genético secundario incluye a $P$. vulgaris, única especie capaz de cruzarse con el frijol ayocote. Finalmente, el acervo terciario incluye las otras especies del género Phaseolus con capacidad para cruzarse, eventualmente con $P$. coccineus como P. acutifolius.

El germoplasma cultivado del acervo genético de $P$. coccineus se clasifica de diferentes maneras. Freytag (1965) reconoce dos razas: 'ayocotes' $(P$. coccineus subsp. coccineus) y 'piloy' ( $P$. coccineus subsp. darwinianus). Dentro de los ayocotes existen dos formas: 'Mexicanos' o ayocotes, plantas con crecimiento de enredadera o tipo arbusto que provienen de climas secos y cálidos; así como los 'Guatemaltecos'o 'botiles', ayocotes con crecimiento de enredadera provenientes de climas fríos y húmedos. También, Delgado-Salinas (1988) indica que el germoplasma, en general, puede dividirse en dos grupos importantes: plantas de enredadera que requieren soporte, aptas para cultivarse en asociación con otras especies como el maíz y plantas arbustivas no trepadoras y erectas. Por otra parte, HernándezXolocotzi et al. (1959) y Cárdenas (1984) proponen la clasificación de ayocotes con base en hábitos de crecimiento, caracteres morfo-agronómicos, ciclos biológicos o sistemas de cultivo.

Las múltiples domesticaciones en el tiempo y/o espacio determinaron la diversidad y estructura genética de los cultivos (Chacón et al., 2005). La domesticación del frijol ocurrió en Mesoamérica y en el sur de los Andes (Gepts \& Bliss, 1985). El germoplasma de $P$. coccineus es claramente diferente tanto en la morfología de la planta como en el grano en comparación con P. vulgaris (Santalla et al., 2004), aunque este puede recombinarse con $P$. coccineus siempre y cuando $P$. vulgaris sea el progenitor femenino (Al-Yasiri \& Coyne, 1965; Miranda, 1990; Singh et al., 2009; Angioi et al., 2009).

El mejoramiento del frijol común y frijol ayocote con el paso del tiempo propició el desarrollo de diversas variedades debido a las cruzas realizadas por el hombre, con el fin de obtener un mayor rendimiento del grano, resistencia a enfermedades y adaptación a diversos ambientes (Singh et al., 2009). Los restos arqueológicos indican que el origen de $P$. coccineus va de Durango a Veracruz en México, y se sugiere que la domesticación ocurrió en las zonas húmedas y altas de los estados de Puebla y Durango (Debouck, 1994). La diversificación de $P$. coccineus ocurrió, en parte, debido a su grado de adaptabilidad respecto a las otras cuatro especies domesticadas de Phaseolus. P. coccineus se distingue por crecer mejor en altitudes superiores a los $1400 \mathrm{msnm}$, temperaturas templadas y altos niveles de precipitación. El peso de 100 semillas de la forma cultivada de $P$. coccineus tiene un peso que oscila entre los 80 a $170 \mathrm{~g}$, y en la forma silvestre es de 6 a $12 \mathrm{~g}$. Las flores son escarlatas o blancas, $\mathrm{y}$ en ocasiones se encuentran ambos colores en una misma flor. La planta florece a los 50 días en variedades tempranas; en la mayoría de los casos presenta polinización cruzada $(12,6-14,7 \%)$ y las semillas de las variedades silvestres se dispersan por dehiscencia natural (Muruaga et al., 1992; Mercati et al., 2013).

El conocimiento de los patrones de diversidad genética podrá incrementar la eficiencia de conservación, utilización y mejoramiento genético del género (Beebe et al., 2000). A pesar de la gran probabilidad de que México sea el centro de origen de P. coccineus (Llaca et al., 1994), pocos son los Estados donde se produce y consume esta leguminosa, y entre los que sobresalen los Estados de México, Puebla, Tlaxcala, Veracruz, Hidalgo, Querétaro, Michoacán, Oaxaca, Guanajuato, San Luis Potosí y Chiapas (Vargas et al., 2007). Sin embargo, $P$. coccineus se consume más que el frijol común en países como España, Italia, Holanda y Reino Unido, tanto como vaina verde fresca (ejote) como en forma de semillas secas. En Hungría, República Checa y Eslovaquia se siembra el frijol ayocote asociado con frijol común (Santalla et al., 
2004). Phaseolus coccineus se utilizó en México como cultivo de cobertura (Navarro et al., 2007) y para la remediación de suelos contaminados con hidrocarburos (Sangabriel et al., 2006). Además, $P$. coccineus se empleó en experimentos con ratas (Rattus spp.) para el tratamiento contra el cáncer de colon (Reynoso et al., 2007), observándose una reducción de la incidencia del cáncer en ratas Sprague-Dawley alimentadas con frijol ayocote (variedad Blanco Tlaxcala) y el frijol común (variedad Pinto Zapata).

\section{Análisis de la diversidad genética y morfológica de} P. coccineus.

En México, alrededor de $90 \%$ de los frijoles silvestres y criollos no están conservados en bancos de germoplasma (Paredes, 2001). El crecimiento desordenado y agresivo de las áreas urbanas del país, la erosión del suelo, el uso excesivo de herbicidas, y los cambios climáticos dan un panorama de alto riesgo sobre los recursos genéticos de Phaseolus. Dentro de este contexto, algunas especies originarias de México, tales como P. chiapasanus y P. xolocotzii, hace años que no se detectan en dicho país (FAO, 1995).

El ADN de cloroplasto (ADNcp) se empleó para reconstruir la filogenia en plantas mediante análisis comparativo de especies a nivel intraespecífico y así establecer grados de parentesco entre especies del complejo Phaseolus (Chacón et al., 2007). Los estudios evolutivos sugieren un solo centro de domesticación de $P$. coccineus, ubicado en el estado de Puebla. A partir del análisis de los patrones de restricción del ADNcp de 30 accesiones de Phaseolus (27 de $P$. coccineus que incluían a $P$. coccineus subsp. darwinianus y $P$. coccineus subsp. glabellus; 3 de $P$. vulgaris y una de $P$. lunatus), Llaca et al. (1994) diferenciaron el germoplasma de Phaseolus a nivel especie. Dichos autores también demostraron que $P$. coccineus presentó mayores niveles de polimorfismo tanto en las accesiones silvestres como en las cultivadas en comparación con el germoplasma de las otras especies estudiadas, así como la mayor afinidad de $P$. coccineus con $P$. darwinianus y $P$. glabellus respectivamente con respecto a $P$. vulgaris (Fig. 2).

Aunque la diversidad genética de $P$. coccineus no ha sido ampliamente estudiada (Brezeanu et al., 2018), existen algunos trabajos al respecto, entre ellos, cabe mencionar el de Sicard et al. (2005) quienes analizaron 66 genotipos representativos de 14 variedades locales de $P$. vulgaris y nueve variedades de $P$. coccineus colectadas en Marche, Italia. La diversidad y las relaciones genéticas del germoplasma de $P$. coccineus se caracterizó mediante marcadores del tipo intersecuencias simples repetidas (ISSRs), secuencias simples repetidas (SSRs) y secuencias simples repetidas de cloroplasto (CpSSRs). Los resultados indicaron que la selección por los agricultores y la adaptación a ambientes heterogéneos es lo que permitió que estas razas de frijol actualmente se mantengan en los cultivos. Se detectaron nueve marcadores polimórficos para $P$. coccineus y ocho para $P$. vulgaris, el índice de diferenciación genética conocido como valor de $\mathrm{F}_{\text {st }}$ (el cual se define como la reducción de heterocigosidad esperada bajo apareamiento aleatorio en un nivel jerárquico en relación con otro nivel superior, atribuible a la diferenciación de poblaciones en los grupos genéticos, cuyos valores oscilan entre 0 y 1 ) indicó valores altos para ambas especies $(0,85$ para $P$. vulgaris y 0,72 para $P$. coccineus). En cuanto al origen, $71 \%$ de las variedades locales de $P$. vulgaris en Marche, Italia, tienen origen Andino, lo cual es útil al momento de proponer estrategias para la conservación de los recursos genéticos de Phaseolus de esas regiones, por ejemplo, realizar cruzas con nuevo germoplasma de origen andino para lograr materiales mejor adaptados a las nuevas condiciones ambientales imperantes, y así asegurar la preservación y productividad del germoplasma.

Por su parte Angioi et al. (2010) estudiaron la dispersión de 307 genotipos europeos de $P$. vulgaris y 94 genotipos de América representativos del acervo Andino y Mesoamericano con seis marcadores microsatélites de cloroplasto más dos de origen nuclear. Sus resultados indican que las rutas de expansión del frijol en Europa son complejas, debido a las diversas introducciones de materiales del Nuevo Mundo y a que, a su vez, fueron mezclados mediante intercambios directos entre países Europeos y Mediterráneos. Otro resultado indicó que el $44 \%$ del germoplasma europeo es derivado de la hibridación de materiales Andinos y Mesoamericanos. Dicho germoplasma se encuentra distribuido en toda Europa, aunque de manera desigual, pues presenta altas frecuencias $(86 \%)$ en Europa Central (Austria, Francia, Holanda, Alemania, Inglaterra y Suecia), y bajas frecuencias 


\section{R. Ruíz-Salazar et al. - El frijol ayocote: recurso genético de México}

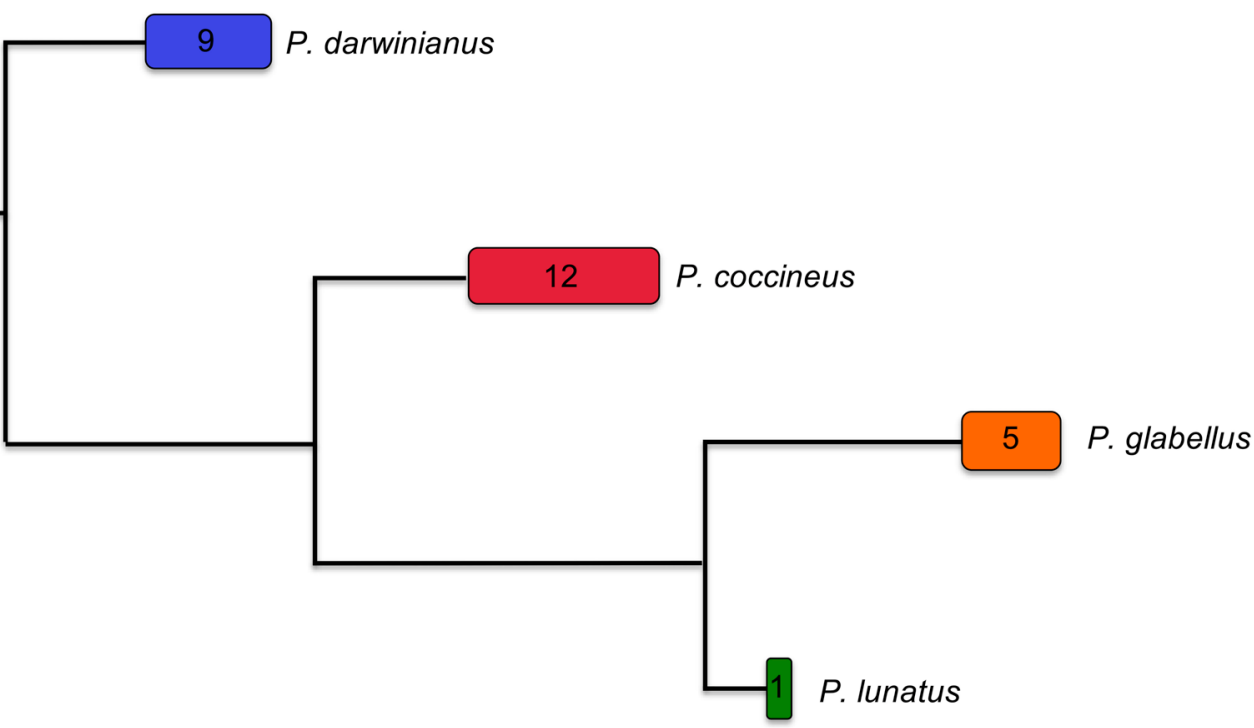

Fig. 2. Análisis molecular de 31 accesiones de Phaseolus. Adaptado de Llaca et al. (1994).

(64\%) en España e Italia. Estos datos, sugieren que el continente europeo es un centro secundario de diversificación de $P$. vulgaris.

En Italia, Spataro et al. (2011) estudiaron la diversidad genética de $P$. coccineus procedente de doce países europeos (Austria, Turquía, Alemania, Hungría, Italia, Polonia, Portugal, Rumania, República Eslovaca, Eslovenia, España y Holanda) y contrastaron con materiales tanto silvestres como cultivados de México, Honduras, Guatemala y Costa Rica. La colección incluyó 148 formas cultivadas de Europa, así como 28 formas silvestres y 52 razas locales de Mesoamérica. Las accesiones se analizaron con 12 marcadores microsatélites; sus resultados destacan la clara diferenciación entre los acervos genéticos europeo y Mesoamericano; la reducción de la riqueza alélica al introducirse en Europa (3,9 alelos en germoplasma europeo; 6,2 alelos en germoplasma Mesoamericano); así como la estrecha relación y el alto flujo genético entre las variedades criollas Mesoamericanas con las formas silvestres de la especie. Spataro et al. (2011) concluyen que la diversidad genética de los materiales silvestres y cultivados son fuente importante para el mejoramiento de Phaseolus spp. y destacaron la necesidad de conservar el germoplasma tanto in situ como ex situ.

Asimismo, Mercati et al. (2015) sugirieron que las variedades criollas del frijol ayocote constituyen una fuente importante de germoplasma para las actividades de mejoramiento en vistas al cambio climático, además de satisfacer los requerimientos de nuevas variedades para áreas marginadas. A partir del análisis de la diversidad y estructura genética de 20 poblaciones de la variedad criolla "Fagiolone" de $P$. coccineus en Italia así como de 41 accesiones de Italia Central y Mesoamérica mediante 14 marcadores moleculares microsatélites, dichos autores mostraron que la variedad "Fagiolone" es de polinización cruzada y que presenta niveles significativos de variación genética intrapoblacional. Asimismo, los resultados 
del análisis filogenético y de estructura poblacional indican que las accesiones Mesoamericanas y las variedades criollas italianas pertenecen a dos grupos genéticos diferentes lo cual confirma la hipótesis de que Europa sería un centro secundario de diversificación de $P$. coccineus (Angioi et al., 2010).

Además de los estudios moleculares en Phaseolus spp. realizados en Europa, cabe mencionar los estudios morfológicos como el de Sinkovic et al. (2019) quienes caracterizaron 953 accesiones de frijol común ( $P$. vulgaris) y 47 accesiones de ayocote (P. coccineus). Los mencionados autores emplearon 14 descriptores de semilla, 6 características cuantitativas a evaluar en cada semilla por accesión (largo, ancho y espesor, proporción largo $\times$ ancho, y ancho $\times$ espesor, peso de 100 o 10 semillas) y 8 características cualitativas (color de semilla, número de colores por semilla, color primario/principal de la semilla, color secundario, distribución del color secundario, forma de la semilla, patrón de líneas de la semilla [vetas] así como el color primario y secundario de la cubierta de la semilla). La variabilidad morfológica de ambas especies fue evaluada mediante un análisis de componentes principales, cuyos cuatro primeros componentes explicaron el $75,03 \%$ y $80,16 \%$ de la variabilidad morfológica de $P$. vulgaris y $P$. coccineus, respectivamente. Asimismo, mediante un análisis de conglomerados, los materiales se agruparon de acuerdo con su origen (Mesoamericano, Andino e híbridos entre ambos acervos) y las rutas de domesticación de ambas especies. Por lo tanto, este estudio es el primero en describir mediante la caracterización morfológica de las semillas, el germoplasma completo de frijol común y ayocote conservado en una de las colecciones de frijol de Europa Central (Eslovenia).

En México, cabe destacar el trabajo realizado por Ramírez et al. (2006) quienes analizaron11 variables cualitativas y 16 cuantitativas de 107 poblaciones de frijol común, 42 de frijol ayocote y una de frijol acalete ( $P$. coccineus subsp. darwinianus) provenientes del Oriente del Estado de México. Los mencionados autores determinaron que la variación entre poblaciones de frijol común, fue mayor que la variación entre las poblaciones de ayocote para los descriptores color de flor, color de semilla y forma predominante del ápice de la vaina. Las poblaciones de frijol ayocote fueron más diversas en cuanto al color de la semilla (54,8\% morado, 26,2\% negro y 19,0\% blanco y café) y formaron dos grupos de accesiones definidos según la precocidad, el número de semillas por vaina y el tamaño de la semilla. La diversidad del frijol común fue mayor respecto a la del frijol ayocote, lo cual probablemente se debe al intercambio de semillas en los mercados regionales, además de su empleo en los sistemas de cultivo tradicionales de asociación maíz-frijol.

En cuanto a los estudios de caracterización molecular de este recurso en México, se encuentra el de Ruíz-Salazar et al. (2019) quienes evaluaron la diversidad genética de 117 colectas de frijol ayocote ( $P$. coccineus) de la Subprovincia Carso Huasteco de Puebla, mediante marcadores moleculares AFLP (Amplified Fragment Length Polymorphism). A partir de cuatro combinaciones de oligonucleótidos, obtuvieron un valor de Fst $=$ 0,93 , lo que indica una alta diferenciación genética entre accesiones. También encontraron una mayor proporción de la varianza molecular dentro de las accesiones $(79,02 \%)$ que entre accesiones $(21,98 \%)$ y sugirieron que dichos resultados podrían deberse a la alogamia de la especie $(14,7 \%)$. Asimismo, debido a la alta diferenciación genética presente en el ayocote, recomendaron incorporar estas accesiones en futuros programas de mejoramiento de Phaseolus spp.

Por otra parte, estudios previos demostraron que esta especie cuenta con el potencial para el desarrollo de resistencia genética a enfermedades y a bajas temperaturas (Delgado-Salinas, 1988; Santalla et al., 1998; Mahuku et al., 2003; Rodiño et al., 2006; Singh et al., 2009). En este sentido, se puede mencionar el trabajo realizado por RuízSalazar et al. (2016) quienes identificaron fuentes de resistencia al tizón común, el virus del mosaico común del frijol, el virus del mosaico dorado del frijol y mancha angular en accesiones de frijol ayocote mediante marcadores moleculares de secuencia caracterizada de regiones amplificadas (SCAR). Para ello estudiaron el germoplasma de frijol ayocote colectado en los estados de Veracruz y Puebla (México) el cual incluyó 152 accesiones de $P$. coccineus (137 cultivadas y 15 silvestres) además de siete accesiones de $P$. vulgaris cultivadas, tres variedades de $P$. vulgaris (Pinto Villa, BAT $477 \mathrm{y}$ Pinto UI-114); se empleó también una accesión $P$. glabellus y una de P. lunatus. Las frecuencias de amplificación de marcadores SCAR promedio para el estado de Veracruz fue 5,97 para tizón común, 


\section{R. Ruíz-Salazar et al. - El frijol ayocote: recurso genético de México}

10,25 para virus del mosaico común del frijol, 13,25 para virus del mosaico dorado del frijol y 12,50 para mancha angular; mientras que para Puebla fue 1,75 para tizón común, 4,75 para virus del mosaico común del frijol, 4,82 para virus del mosaico dorado del frijol y 4,5 para mancha angular. Por este motivo, los autores proponen que a pesar de que las accesiones del estado de Veracruz poseen en promedio ocho SCAR más que las de Puebla, principalmente para virus del mosaico dorado y mancha angular, ambas poblaciones sean empleadas en programas de mejoramiento genético para incorporar resistencia genética a genotipos de interés.

Uso y aprovechamiento de los recursos genéticos de P. coccineus.

El uso de germoplasma silvestre es necesario para transferir genes deseables a las formas cultivadas de Phaseolus, puesto que las especies silvestres tienen características favorables para la adaptación a diversas condiciones ambientales (Acosta et al., 1996). Mediante el uso de la selección asistida por marcadores moleculares se ha logrado transferir genes con características favorables a nivel de especie en el género Phaseolus (Yu et al., 2000). Diversos estudios han encontrado suficiente variación genética en la mayoría de las características de calidad determinadas en Phaseolus (tamaño de la semilla, grosor de la testa y cantidad de proteína) por lo que existe la posibilidad de mejoramiento mediante recombinación y selección (Pérez et al., 2002).

El germoplasma de variedades nativas también es fuente de variabilidad genética que se ha utilizado en el mejoramiento genético del frijol. Existen bajo conservación ex situ extensas colecciones de cada una de las cinco especies domesticadas, sin embargo, el manejo de las colecciones grandes de germoplasma para mejoramiento genético es difícil por los altos costos que implica. La colección

Tabla 1. Distribución geográfica y características edafoclimáticas de sitios originales de colecta de variedades nativas de $P$. coccineus conservadas ex situ en INIFAP, México. ${ }^{*}=$ el $50 \%$ de las accesiones son del Estado de Puebla, en los demás estados el porcentaje de colectas varía entre 0,9\% y $13,4 \%$.

Variable

Entidad federativa

Rango altitudinal

Región natural

Provincia y subprovincia fisiográfica

Tipo de suelo

Tipo de clima

Tipo de vegetación

\section{Descriptor}

Puebla, Estado de México, Tlaxcala, Veracruz, Querétaro, Hidalgo, Michoacán, Oaxaca, San Luis Potosí, Guanajuato y Chiapas.

El 50,3 \% (401 accesiones) corresponden a altitudes entre 2000 y 2600 msnm; 39,1 (302) de 1400 a 2000; 6,1 (49) de 800 a 1400; 4,4 (35) alturas superiores a 2600. Sólo una accesión fue colectada a una altura inferior a los $800 \mathrm{msnm}$.

El $72,3 \%$ del germoplasma pertenece a zonas templadas, el $11,4 \%$ a zonas áridas, $8,4 \%$ al trópico subhúmedo, y 7,9 pertenecen al trópico húmedo.

En México hay seis provincias fisiográficas y 18 subprovincias. Las más representadas con el Eje Neovolcánico (53\%); Sierra Madre Oriental (28); Sierra del Sur (13); Mesa del Centro (5); Sierra de Chiapas, Guatemala y la Cordillera Centroamericana (1). Las Subprovincias más representadas son el Eje Neovolcánico (Lagos y volcanes del Anáhuac, y Llanuras y Sierras de Querétaro e Hidalgo); Sierra Madre Oriental (Carso Huasteco); Sierra Madre del Sur (Sierras Orientales y Mil Cumbres); Mesa del Centro (Sierras y Llanuras del Norte de Guanajuato) y Sierra de Chiapas y Guatemala (Sierras del Norte de Chiapas).

El tipo de suelo predominante para los sitios de colecta es el Cambisol Éútrico (45\%), Feozem Háplico (18), Andosol Mólico (10), Andosol Úmbrico (6) y Leptosoles (15) El 6\% restante proviene de sitios con suelos Regosol, Vertisol, Alisol, Calcisol, Arenosol, Acrisol y Nitisol.

El $62 \%$ de las accesiones colectadas pertenece a sitios con clima templado húmedo y/o subhúmedo, $18 \%$ a climas cálidos y semicálidos, $15 \%$ a climas áridos y semiáridos, y solo $5 \%$ a climas semifríos.

El $74 \%$ proviene de sitios boscosos, el $11 \%$ de la sabana arbustiva, $10 \%$ a vegetación semidesértica, y $5 \%$ provienen de la alta montaña 
nacional de germoplasma de frijol ayocote del Instituto Nacional de Investigaciones Agrícolas y Pecuarias (INIFAP) de México está conformada por 798 accesiones, que cuentan con información geográfica de los sitios de colecta (Vargas et al., 2012). (Tabla 1).

La variabilidad genética y fenotípica de las accesiones está influenciada por los factores climáticos donde crece y se presume evolucionó la especie. El rango de precipitación de los 140 sitios de colecta de las 798 variedades nativas es de 500 a $1000 \mathrm{~mm}$ de precipitación anual. El rango de temperatura mínima y máxima media anual separó los sitios en: muy fríos (de -5 a 1 ${ }^{\circ} \mathrm{C}$ en la noche y 21 a $31{ }^{\circ} \mathrm{C}$ en el día), fríos (de 3 a $5{ }^{\circ} \mathrm{C}$ y 25 a $33{ }^{\circ} \mathrm{C}$ ) y semifríos (de 6 a $9{ }^{\circ} \mathrm{C}$ y 25 a $37{ }^{\circ} \mathrm{C}$ ). Dada la amplitud de los rangos de precipitación y temperatura que ocurre en un año, se infiere la posible existencia de plasticidad fenológica en las plantas de esta colección (VargasVázquez et al., 2018). Por ejemplo, los ayocotes de la subprovincia fisiográfica Carso Huasteco de México, se diferenciaron en dos grupos: de ciclo biológico tardío $>110$ días y semillas grandes desarrollados por selección empírica de campesinos locales en sitios con temperatura mínima de 2 a $5^{\circ} \mathrm{C}$; y los de ciclo precoz $<110$ días y semilla chica cultivados en sitios con temperatura mínima de 0 a $-2^{\circ} \mathrm{C}$ (Vargas-Vázquez et al., 2011).

\section{Trabajos con P. coccineus.}

El estudio y manejo de la diversidad genética de frijol común es limitado. La introgresión de $P$. coccineus $\times P$. vulgaris ha sido exitosa para la obtención de plantas resistentes a enfermedades bacterianas (Xanthomonas sp.) (Santalla et al., 2004); Rhizoctonia solani (Beaver et al., 2007); Fusarium sp. y Sclerotinia sclerotiorum (Santalla et al., 2004; Singh et al., 2009, 2014; Viteri \& Singh, 2014). Las bajas temperaturas retrasan la germinación y la emergencia de las plantas de $P$. vulgaris mientras que $P$. coccineus es una especie que soporta temperaturas moderadamente bajas para su germinación. Rodiño et al. (2006) identificaron ayocotes tolerantes a bajas temperaturas $\left(14 / 8{ }^{\circ} \mathrm{C}\right.$ día/noche) durante el proceso de germinación; accesiones PI325592, PI510637, PI313313, PI325608, PI535276 (cultivares de México, bajo resguardo del Departamento de Agricultura de los Estados Unidos). Por otra parte, se realizaron estudios de fitoremediación de suelos contaminados con hidrocarburos y se demostró que $P$. coccineus tolera y crece en estas condiciones, debido a una mayor población rizosférica de bacterias y hongos en contraste con otras cinco especies (Cicer arietinum L., Clitoria ternatea L., Panicum máximum Jacq., Brachiaria brizantha (Hochst. ex A. Rich.) Stapf y Brachiaria híbrido) empleadas en dicho estudio (Sangabriel et al., 2006).

Asimsmo, estudios realizados en ratas (Rattus sp.) demostraron que el consumo de frijol en cantidades apropiadas reduce el cáncer de colon. El cáncer fue inducido mediante la inyección de 1,2 dimetilhidrazina (DMH). Luego, las ratas fueron alimentadas con cantidades de granos de tres variedades de de gran demanda en México ( $P$. vulgaris: Flor de Junio Marcela, Pinto Zapata y Flor de Mayo Anita) y P. coccineus: Blanco Tlaxcala) similares al promedio de consumo actual $(0,30 \mathrm{~g}$ $100 \mathrm{~g}^{-1}$ de alimento, que equivale a $11 \mathrm{~kg}$ persona ${ }^{-1}$ al año). Las ratas alimentadas con frijol Blanco

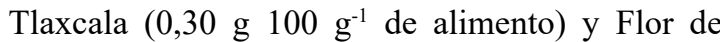
Junio Marcela (75 g $100 \mathrm{~g}^{-1}$ ), disminuyeron entre 10 y $12 \%$ la carcinogénesis del colon. El consumo de la variedad de frijol Pinto Zapata redujo hasta un $36 \%$ la incidencia de tumores (Reynoso et al., 2007).

También se detectaron genes que confieren resistencia al virus del mosaico dorado amarillo del frijol (BGYMV por sus siglas en inglés) en la accesión G35172 de $P$. coccineus del CIAT de Colombia y estos se han introgresado al frijol común. El gen recesivo bgm-3 confiere resistencia a clorosis foliar y el dominante $B g p-2$ previene la deformación de la vaina, por lo que los dos genes de $P$. coccineus pueden contribuir a incrementar la resistencia al BGYMV en frijol común (Osorno et al., 2007).

Un estudio con $P$. coccineus reveló que la especie posee niveles de resistencia elevados a Phaeoisariopsis griseola (Sacc.). Este patógeno es el causante de la enfermedad conocida como mancha angular, la que constituye un serio problema al rendimiento del frijol debido a que ocasiona severas pérdidas de granos (Busogoro et al., 1999). Por otra parte, se comparó la aptitud para cobertura vegetal del suelo y la producción de grano entre P. coccineus, dos variedades de Vicia faba L., $V$. sativa L. y Avena sativa L., así como la producción de grano de todos ellos. Los mayores rendimientos 


\section{R. Ruíz-Salazar et al. - El frijol ayocote: recurso genético de México}

de grano los mostraron $P$. coccineus y $V$. sativa con $2.96 \mathrm{t} \mathrm{ha}^{-1}$ y $1.06 \mathrm{t} \mathrm{ha}^{-1}$, respectivamente $\mathrm{y}$, en cuanto a la cobertura, $V$. sativa y $A$. sativa presentaron los mayores porcentajes a los 30,61 , 86 y 126 días después de la siembra (Navarro et al., 2007). En Rumania se evaluó el rendimiento de $P$. coccineus en dos años consecutivos de producción en monocultivo y en asociación con plantas de maíz (V4); de girasol (V5) y de alcachofa (V6). Los ensayos se realizaron en enrejados de madera con doble hilera, una cuerda (V1); con hilera simple, una cuerda (V2) y con hilera simple en red sintética (17 cm de luz de malla) (V3). Los rendimientos fueron de 3,61 tha-1 (V2) a 1,68 $\mathrm{t} \mathrm{ha}^{-1}(\mathrm{~V} 6)$ (primer año) y $3,17 \mathrm{t} \mathrm{ha}^{-1}$ (V2) a $1,18 \mathrm{t} \mathrm{ha}^{-1}$ (V6) (segundo año); el contenido de proteína cruda fue del $22,65 \%$ (V6) a $25,47 \%$ (V3); el de grasa total de 1,91\% (V6) a $2,16 \%$ (V4) y el contenido de fibra total fue de $5,41 \%$ (V4) a 5,81\% (V5) (Hamburdâ et al., 2016). Phaseolus coccineus presenta tolerancia a la salinidad durante su desarrollo, por ello, se evaluaron 132 accesiones de 14 especies silvestres ( $P$. acutifolius Gray, P. angustissimus A. Gray, P. carteri Freytag \& Debouck, P. filiformis Bentham, P. glabellus Piper, P. leptostachyus Bentham, P. lunatus L., P. micranthus Hook \& Arnold, P. microcarpus Mart., P. mcvaughii A. Delgado, $P$. oligospermus Piper, y $P$. vulgaris L.) y 11 accesiones que representan 5 especies cultivadas ( $P$. acutifolius, $P$. coccineus, $P$. lunatus, $P$. polyanthus, y $P$. vulgaris) en soluciones desde 0 hasta $180 \mathrm{mM}$ de $\mathrm{NaCl}$ durante 21 días. Las accesiones silvestres de $P$. acutifolius, P. filiformis, $P$. lunatus y $P$. vulgaris mostraron un amplio rango de variación en su tolerancia a salinidad $(180 \mathrm{mM})$ con base en los valores de biomasa entre tratamientos. En cambio, se observó una menor tolerancia a la salinidad $(100 \mathrm{mM})$ en las accesiones silvestres de P. micranthus, P. filiformis, P. mcvaughii, $P$. lunatus, $P$. vulgaris y en las cultivadas de $P$. coccineus; siendo las accesiones $P$. filiformis las más tolerantes ( 9 de 11 accesiones). En cambio, la accesión silvestre de $P$. vulgaris fue más tolerante a la salinidad que las tres accesiones cultivadas de la misma especie (Bayuelo-Jiménez et al., 2002).

Por otro parte, aunque las proteínas presentes en las leguminosas cuentan con péptidos bioactivos con fines nutracéuticos (Paredes \& Valverde, 2006), en el frijol ayocote es poco es lo que se sabe al respecto. Por este motivo, Teniente-Martínez et al. (2016) evaluaron la influencia de la accesión sobre la composición química del frijol así como la capacidad citotóxica de los péptidos generados por la hidrólisis enzimática de cada aislado proteico. El análisis proximal de la colecta de frijol negro contiene mayor cantidad de proteína $(23,8 \%)$ que la de frijol morado (21,9\%); mientras que el contenido de cenizas, grasas y carbohidratos es mayor en el frijol morado. El punto isoeléctrico de las proteínas de ambas colectas se encuentra en un $\mathrm{pH}$ de 4,0, no hubo diferencias entre los tratamientos para detección de actividad citotóxica en seis grupos de ratones de laboratorio alimentados con distintos niveles (10, 100, 1000, 1600,2900 , y $5000 \mathrm{mg}$ ) del aislado peptídico.

Por último, cabe mencionar que el cruzamiento interespecífico de $P$. vulgaris con $P$. coccineus es posible, siempre y cuando $P$. vulgaris sea el progenitor femenino (Miranda, 1990; Angioi et al., 2009). Además de ser una especie evolutivamente estable por largos periodos de tiempo mediante autopolinización o a través de entrecruzamientos con otras especies afines (González et al., 2014). En la Fig. 3 se observa la semejanza morfológica entre $P$. coccineus (grupo 1) y el híbrido natural. Se considera que el híbrido proviene del cruzamiento natural entre $P$. vulgaris y $P$. coccineus (grupo 2). Por todo lo anterior, es necesario enfatizar la importancia que $P$. coccineus representa como especie viable para la producción de grano $\boldsymbol{y}$ la potencial contribución en programas de mejoramiento genético del frijol común.

El Banco de Germoplasma de Phaseolus del Centro Internacional de Agricultura Tropical (CIAT) consigna 37.485 accesiones de las especies domesticadas: 32.416 de $P$. vulgaris, 3.305 de $P$. lunatus, 975 de $P$. coccineus, 490 de $P$. dumosus y 316 de $P$. acutifolius (CIAT, 2021). De dichas especies, $P$. vulgaris, $P$. coccineus y $P$. dumosus muestran los cinco diferentes estadios biológicos del género: silvestre, cultivado, 'escapado', regresivo e híbrido; P. lunatus no muestra híbridos y $P$. acutifolius solo tiene formas silvestres y cultivadas. Dicha información nos permite inferir que desde el punto de vista tradicional $P$. lunatus y $P$. acutifolius muestran un alto grado de dificultad para ser utilizadas en el mejoramiento tradicional del frijol común y sólo podrán incorporarse a éste con el apoyo de herramientas biotecnológicas. 
Bol. Soc. Argent. Bot. 56 (3) 2021

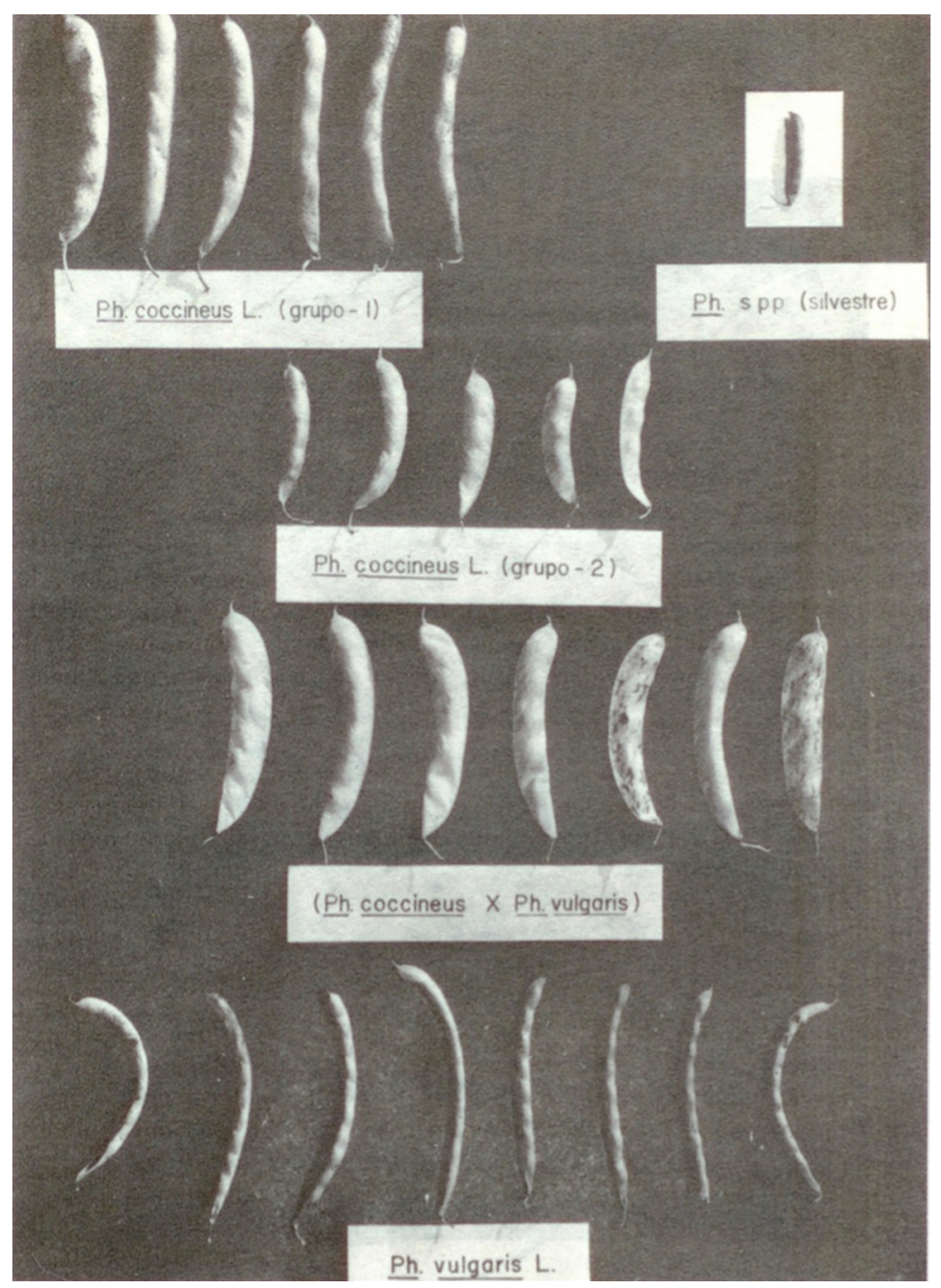

Fig. 3. Características de la vaina de ayocote, $P$. vulgaris $\times$. coccineus (híbrido natural) y $P$. vulgaris. Los grupos 1 y 2 de $P$. coccineus son poblaciones que difieren desde el punto de vista morfológico. Fuente: Miranda, 1990, con autorización del autor.

\section{Discusión}

Los recursos genéticos del frijol ayocote $(P$. coccineus) en México no han tenido la atención suficiente para su valoración como el frijol común. Se reconoce que el frijol ayocote es la segunda especie de las cinco especies domesticadas. Esto se refleja en el número de registros de colectas almacenadas en el Banco de Germoplasma del Centro Internacional de Agricultura Tropical (CIAT) en Cali, Colombia. (CIAT, 2021). Además, en las 958 accesiones de que esta especie están representados todos los estados biológicos que incluyen los tipos cultivados, silvestres; escapados, regresivos e híbridos. También se conoce que en México la superficie de siembra de esta especie no supera las 1000 hectáreas en los estados principales (Chiapas, Durango, México, Puebla, Tlaxcala y Zacatecas) (Muruaga 2017, comunicación personal). En la actualidad, sólo continúan con su cultivo en los sitios de agricultura tradicional. En este contexto es válido afirmar que los recursos genéticos de esta especie como producto del proceso de la evolución natural y del proceso de domesticación constituye 


\section{R. Ruíz-Salazar et al. - El frijol ayocote: recurso genético de México}

una base imprescindible para la alimentación y el bienestar de la población en las regiones templadas de los valles altos de México. Por ello es imperativo que los países conserven sus recursos genéticos para la alimentación y la agricultura con la finalidad de aumentar sus niveles de producción agrícola de manera sostenible y redituable, para hacer frente a los desafíos que plantean los constantes cambios del ambiente.

Hasta el momento, los estudios tanto genéticos como morfológicos en $P$. coccineus en México son escasos, destacándose los estudios de la variación morfológica entre y dentro de $P$. vulgaris y $P$. coccineus del Centro de México. En Europa, $P$. coccineus se utilizó como fuente de resistencia a enfermedades, frío, salinidad y otros factores adversos. Además, se empleó como cultivo de cobertura y remediación de suelos; en estudios para el tratamiento contra el cáncer de colon y en pruebas de tolerancia a la salinidad como especie cultivada. En estos trabajos quedaron demostradas las cualidades de esta especie en cuanto a los beneficios que aporta al hombre y al ambiente, por lo que es necesario profundizar en su investigación y así obtener un mayor rendimiento de grano y resistencia a los principales patógenos que afectan al cultivo de frijol en México, como lo son la antracnosis y el tizón común. Es necesario destinar mayor atención y recursos a esta especie para obtener resultados que ayuden a mitigar la carencia de este grano en México.

\section{Conclusiones}

El frijol ayocote en México, a pesar de su consumo, fue clasificado como una especie marginada debido principalmente al desconocimiento de sus potencialidades. Por lo tanto, una buena estrategia para su preservación, difusión y uso podría ser la realización de estudios morfológicos y moleculares que permitan conocer la diversidad genética de la especie e identificar accesiones con características de interés (por ejemplo genes de resistencia a enfermedades), que pueden ser incorporadas a programas de mejoramiento genético. Otra alternativa puede ser el desarrollo de nuevas técnicas para el manejo, uso y aprovechamiento de esta leguminosa, ya sea para consumo humano o forraje. Dado que se trata de una especie perenne también se requieren estrategias que permitan su manejo integral. Por último, en cuanto a la conservación de los distintos materiales de esta especie, es necesario crear bancos de germoplasma que permitan preservar las semillas a largo plazo en buenas condiciones que promuevan su viabilidad y posterior propagación.

\section{Contribución de los Autores}

RRS recabó entrevistas con especialistas del área, realizó la búsqueda de la información en distintos medios electrónicos e impresos y elaboró la redacción general, NMP organizó la presentación de la información, SHD y MLPVV participaron como revisores del manuscrito.

\section{Agradecimientos}

El primer autor agradece al Consejo Nacional de Ciencia y Tecnología de México la beca (\# 10209), al IPN, Santander-ECOES Universia y CONACYT (beca de ayudante de investigador S.N.I. nivel 3) por otorgar becas para su estudio doctoral en el CBG-IPN. También agradece al Dr. Salvador Miranda-Colín (profesor emérito del Colegio de Postgraduados, Montecillo, México) por sus observaciones y sugerencias al presente escrito. Este trabajo y sus costos de publicación son cubiertos por el proyecto \# 181756 (CONACYTCiencia Básica) y el proyecto Multidisciplinario SIP-IPN \# 1636.

\section{Bibliografía}

ACOSTA, J.A., J.S. MURUAGA, F. CÁRDENAS \& M.M. KHAIRALLAH. 1996. Estrategias para la utilización de germoplasma de Phaseolus en el mejoramiento genético. Ciencia 47: 149-160.

AL-YASIRI, S.A. \& D.P. COYNE. 1965. Interspecific hibridization in the genus Phaseolus. Crop Sci. 6: 59-60.

ANGIOI, S.A., F. DESIDERIO, D. RAU, E. BITOCCHI, G. ATTENE \& R. PAPA. 2009. Development and use of chloroplast microsatellites in Phaseolus spp. and other legumes. Plant Biology 11: 598-612. https://doi.org/10.1111/j.1438-8677.2008.00143.x 
ANGIOI, S.A., D. RAU, G. ATTENE, L. NANNI, E. BELluCCI, G. LOGOZZO, V. NEGRI, P.L. SPAGNOLETTI-ZEULI \& R. PAPA. 2010. Beans in Europe: origin and structure of the European landraces of Phaseolus vulgaris L. Theor Appl Genet. 121: 829-843.

https://doi.org/10.1007/s00122-010-1353-2

BAYUELO-JIMÉNEZ, J.S., D.G. DEBOUCK \& J.P. LYNCH. 2002. Salinity tolerant of Phaseolus species during early vegetative growth. Crop Sci. 42: 2184-2192.

https://doi.org/10.2135/cropsci2002.2184

BEAVER, J., M. ALAMEDA, \& J.C. ROSAS. 2007. Mejoramiento de frijol para resistencia a la mustia hilachosa. p. 60. En Resúmenes de la LIII Reunión Anual del Programa Cooperativo Centroamericano para el Mejoramiento de cultivos y Animales, Instituto de Ciencias y Tecnologías Agrícolas, Antigua Guatemala, Guatemala.

BEEBE, S., P.W. SCKROCH, J. TOHME, M.C. DUQUE, F. PEDRAZA, \& J. NIENHUIS. 2000. Structure of genetic diversity among common bean landraces of Middle American origin based on correspondence analysis of RAPD. Crop Sci. 40: 264-273.

https://doi.org/10.2135/cropsci2000.401264x

BELLÓN M.R., J. BERTHAUD, M. SMALE, J.A. AGUIRRE, S. TABA, F. ARAGÓN, J. DÍAZ \& H. CASTRO. 2003. Participatory landrace selection for on-farm conservation: An example from the Central Valleys of Oaxaca, México. Gen. Res. Crop. Evolution 50: 401-416. https://doi.org/10.1023/A:1023967611495

BITOCCHI, E., L. NANNI, E. BELLUCCI, M. ROSSI, A. GIARDINI, P. SPAGNOLETTI-ZEULi, P. LOGOZZO, J. STOUGAARD, P. MCCLEAN, G. ATTENE \& R. PAPA. 2012. Mesoamerican origin of the common bean (Phaseolus vulgaris L.) is revealed by sequence data. Proc. Nat. Acad. Sci. 109: 788796. https://doi.org/10.1073/pnas.1108973109

BUSOGORO, J.P., M.H. JIJAKLI \& P. LEPOIVRE. 1999. Identification of a novel source of resistance to angular leaf spot disease of common bean within the secondary gene pool. Plant Breed. 118: 417-423. https://doi.org/10.1046/j.1439-0523.1999.00413.x

BREZEANU, C., S. AMBARUS, P.M. BREZEANU \& C.A. ANTAL. 2018. Study of Phaseolus coccineus biodiversity in order to select valuable germplasm. Biologie 27:124-127.

CÁRDENAS, R.F. 1984. Clasificación preliminar de los frijoles en México. Ex Secretaría de Agricultura y
Recursos Hidráulicos SARH y Ex Instituto Nacional de Investigaciones Agrícolas INIA. Folleto técnico Núm. 81 México, D. F. 19 p.

CHACÓN, I.R., S.B. PICKERSGILL \& D.G. DEBOUCK. 2005. Domestication patterns in common bean (Phaseolus vulgaris L.) and the origin of the Mesoamerican and Andean cultivated races. Theor. Appl. Genet. 110: 432-444. https://doi.org/10.1007/s00122-004-1842-2

CHACÓN, I.R., B. PICKERSGILL, D.G. DEBOUCK \& J.A. SALVADOR. 2007. Phylogeographic analysis of the chloroplast DNA variation in wild common bean (Phaseolus vulgaris L.) in the Americas. Plant. Syst. Evol. 1: 1-21. https://doi.org/10.1007/s00606-007-0536-z

CIAT. 2021. Bean collection. Disponible en: https:// genebank.ciat.cgiar.org/genebank/bshowcollec tion. do?type $=$ search $\&$ by $=$ showall $\&$ collection $=$ bean $\& n$ ew $=$ new\&category $=$ última fecha de visita 01 de febrero de 2021.

CORZO-RÍOS, L.J., X.M. SÁNCHEZ-CHINO, A. CARDADOR-MARTÍNEZ，J. MARTÍNEZHERRERA \& C. JIMÉNEZ-MARTÍNEZ. 2020. Effect of cooking on nutritional and non-nutritional compounds in two species of Phaseolus (P. vulgaris and $P$. coccineus) cultivated in Mexico. Int. J. of Gastr. and Food Sci. 20:100206.

https://doi.org/10.1016/j.ijgfs.2020.100206

DEBOUCK, D.G. 1994. Beans (Phaseolus spp.). In Neglected crops: from a different perspective. p. 47-62. In J.E. Hernando B. and J. Leon (eds.). Plant Production and Protection Series No. 26. FAO, Rome, Italy.

DELGADO-SALINAS, A. 1985. Systematics of the genus Phaseolus (Leguminosae) in Mexico and Central America. Ph.D. dissertation. University of Texas, Austin, Texas, USA.

DELGADO-SALINAS, A. 1988. Variation, taxonomy, domestication, and germplasm potentialities in Phaseolus coccineus. In: P. Gepts (ed.). Genetic Resources of Phaseolus Beans. pp. 441-463. Kluwer. Dordrecht, The Netherlands. https://doi.org/10.1007/978-94-009-2786-5_18

DELGADO, S.A., R. BIBLER \& M. LAVIN. 2006. Phylogeny of the genus Phaseolus (Leguminosae): A recent diversification in an ancient landscape. Syst. Bot. 3: 779-791. https://doi.org/10.1600/036364406779695960

FAO. 1995. Anexo 2 del Informe de la Reunión Subregional sobre los Recursos Fitogenéticos para 


\section{R. Ruíz-Salazar et al. - El frijol ayocote: recurso genético de México}

América Central, México y el Caribe. p. 1-57. Organización de las Naciones Unidas para la Agricultura y la Alimentación (FAO). San José, Costa Rica.

FREYTAG, G.F. 1965. Clasificación del frijol (Phaseolus vulgaris L.) y especies afines. Ceiba (Honduras) 11(1):51-64.

FREYTAG, G. \& D. DEBOUCK. 2002. Taxonomy, distribution, and ecology of the genus Phaseolus (Leguminosae-papilionoideae) in North America, Mexico and Central America. Botanical Research Institute of Texas (BRIT), Forth Worth, TX, USA. 298 p. (Sida, Botanical Miscellany no. 23)

GEPTS, P. \& F. BLISS. 1985. $\mathrm{F}_{1}$ hibrid weakness in the common bean. J. Hered. 76: 447-450.

https://doi.org/10.1093/oxfordjournals.jhered. a110142

GONZÁleZ, A., A. DE RON, M. LORES \& M. SANTALLA. 2014. Effect of the inbreeding depression in progeny fitness of runner bean (Phaseolus coccineus L.) and its implications for breeding. Euphytica 200: 413-428.

https://doi.org/10.1007/s10681-014-1177-2

HAMBURDÂ, S., G. TELIBAN, N. MUNTEANU \& V. STOLERU. 2016. Effect of intercropping system on the quality and quantity of runner bean (Phaseolus coccineus L.). Not. Bot. Horti. Agrobo. 44: 613-618. https://doi.org/10.15835/nbha44210260

HARLAN, J. \& DE WET. 1971. Toward a rational classification of cultivated plants. Taxon 20: 509517. https://doi.org/10.2307/1218252

HERNÁNDEZ-LÓPEZ, V., M. VARGAS-VÁZQUEZ, J. MURUAGA-MARTÍNEZ, S. HERNÁNDEZDELGADO \& N. MAYEK-PÉREZ. 2013. Origen, domesticación y diversificación del frijol común: Avances y perspectivas. Rev. Fitotec. Mex. 36: 95104. https://doi.org/10.35196/rfm.2013.2.95

HERNÁNDEZ-XOLOCOTZI, E., S. MIRANDA \& C. PRYWER. 1959. El origen de Phaseolus coccineus L. darwinianus Hdz. X. et Miranda C. subspecies nova. Rev. Soc. Mex. Hist. Nat. 20: 99-121.

KAPLAN, L. 1965. Beans of Wetherill Mesa. Memoirs of the Society for American Archaeology. 19: 153-155.

KAPLAN, L. 1967. Archeological Phaseolus from Tehuacán. In: Beyers, D.E. (ed.). The prehistory of the Tehuacán Valley, vol 1: environment and subsistence. University of Texas, Austin, TX, USA. p. 201-211.

KAPLAN, L. 1980. What is the origin of the common bean? Econ. Bot. 19: 358-368.
KAPLAN, L. \& R. MACNEISH. 1960 "Prehistoric Bean Remains from Caves in the Ocampo Region of Tamaulipas, Mexico." Botanical Museum Leaflets 19(2). Cambridge, Massachusetts: Harvard University Press.

LLACA, V., A. DELGADO \& P. GEPTS. 1994. Chloroplast DNA as an evolutionary marker in the Phaseolus vulgaris complex. Theor. Appl. Genet. 88: 646-652. https://doi.org/10.1007/BF01253966

MARÉCHAL, R., J. MASCHERPA \& F. STAINIER. 1978. Etude taxonomique d'un groupe complexe d'espèces des genres Phaseolus et Vigna (Papilionaceae) sur la base de données morphologiques et polliniques, traitées par l'analyse informatique. Boissiera 28: 1-273.

MAHUKU, G., C. JARA, C. CAJIAO \& S. BEEBE. 2003. Sources of resistance to angular leaf spot (Phaeoisariopsis griseola) in common bean core collection, wild Phaseolus vulgaris and secondary gene pool. Euphytica 130: 303-313. https://doi.org/10.1023/A:1023095531683

MERCATI, F., G. CATARCIONE, A. PAOLACCI, M. ABENAVOLI, F. SUNSERI \& M. CIAFFI. 2015. Genetic diversity and population structure of an Italian landrace of runner bean (Phaseolus coccineus L.): inferences for its safeguard and onfarm conservation. Genetica 143: 473-485.

https://doi.org/10.1007/s10709-015-9846-1

MERCATI, F., M. LEONE, A. LUPINI, A. SORGONÀ, M. BACCHI, M. ABENAVOLI \& F. SUNSERI. 2013. Genetic diversity and population structure of a common bean (Phaseolus vulgaris L.) collection from Calabria (Italy). Genet. Resourc. Crop Evol. 60: 839-852.

https://doi.org/10.1007/s10722-012-9879-6

MIRANDA, S. 1990. Infiltración genética de Phaseolus vulgaris en Phaseolus coccineus. 58 p. Centro de Genética, Campus Montecillo. Texcoco, Estado de México.

MONROY, R. \& A. QUEZADA-MARTÍNEZ. 2010. Estudio etnobotánico del frijol yepatlaxtle (Phaseolus coccineus L.) en el área natural protegida Corredor Biológico Chichinautzin, Morelos, México. Av. Inv. Agrop. (U. Colima) 14: 23-34.

MURUAGA, J., F. CÁRDENAS \& J. ACOSTAGALLEGOS. 1992. Hibridación natural y métodos de polinización manual en Phaseolus coccineus L. p. 307-311. In Memoria de la XXXVIII Reunión Anual Programa Cooperativo Centroamericano para el Mejoramiento de Cultivos Alimenticios y Animales. Managua, Nicaragua. 
NAVARRO, H., M.A. PÉREZ \& F. CASTILLO. 2007. Evaluación de cinco especies vegetales como cultivos de cobertura en valles altos de México. Rev. Fitotec. Mex. 30: 151-157.

OSORNO, J., F. FERWERDA, M. BASSET, P. MIKLAS, T. OLCZYK \& B. BUSSEY. 2007. Two genes from Phaseolus coccineus confer resistance to Golden Yellow Mosaic Virus in common bean. J. Amer. Soc. Hort. Sci. 132: 530-533. https://doi.org/10.21273/JASHS.132.4.530

PAREDES, O. 2001. Pérdida de la riqueza genómica. Disponible en http://www.jornada.unam. $\mathrm{mx} / 2001 / 04 / 30 /$ cien-lopez.html. (Consulta $01 \mathrm{de}$ febrero de 2021).

PAREDES, O. \& M. VALVERDE. 2006. Los recursos nutracéuticos y medicinales que Mesoamérica le ha dado al mundo. CINVESTAV 25: 65-73.

PÉREZ, P., G. ESQUIVEL, R. ROSALES \& J. ACOSTAGALLEGOS. 2002. Caracterización física, culinaria y nutricional de frijol del altiplano subhúmedo de México. Arch. Lat. Nutr. 52: 172-180.

PIÑERO, D. \& L. EGUIARTE. 1988. The origin and biosystematic status of Phaseolus coccineus ssp. polyanthus: electrophoretic evidence. Euphytica 37: 199-2013.

RAMÍREZ, P., M. CASTILLO, F. CASTILLO \& S. MIRANDA. 2006. Diversidad morfológica de poblaciones nativas de frijol común y frijol ayocote del Oriente del estado de México. Rev. Fitotec. Mex. 29: 111-119.

REYES-RIVAS, E., L. PADILLA-BERNAL, O. PÉREZVEYNA \& P. LÓPEZ-JÁQUEZ. 2008. Historia, naturaleza y cualidades alimentarias del frijol. Rev. Inv. Cientifica 4: 1-21.

REYNOSO, C., M. RÍOS-UGALDE, I. TORRESPACHECO, J. ACOSTA-GALLEGOS, A. PALOMINO-SALINAS, M. RAMOS-GÓMEZ, E. GONZÁLEZ-JASSO \& S. GUZMÁNMALDONADO. 2007. El consumo del frijol común (Phaseolus vulgaris L.) y su efecto sobre el cáncer de colon en ratas Sprague-Dawley. Agric. Téc. Méx. 33: 43-52.

RODIÑO, A., M. LEMA, B. PÉREZ, M. SANTALLA \& A. DE RON. 2006 Assessment of runner bean (Phaseolus coccineus L.) germplasm for tolerance to low temperature during early seedling growth. Euphytica 155: 63-70.

https://doi.org/10.1007/s10681-006-9301-6

RODRÍGUEZ-LICEA, G., J. GARCÍA-SALAZAR, S. REBOLLAR-REBOLLAR \& A. CRUZ-
CONTRERAS. 2010. Preferencias del consumidor de frijol (Phaseolus vulgaris L.) en México: factores y características que influyen en la decisión de compra diferenciada por tipo y variedad. Paradigma Económico 2: 121-145.

RUÍZ-SALAZAR, R., N. MAYEK-PÉREZ, M. VARGAS-VÁZQUEZ, S. HERNÁNDEZDELGADO \& J. MURUAGA-MARTÍNEZ. 2019. Análisis de la estructura poblacional de frijol ayocote (Phaseolus coccineus L.) mediante AFLP. Polibotánica 47: 13-24.

https://doi.org/10.18387/polibotanica.47.2

RUÍZ-SALAZAR, R., J. MURUAGA-MARTÍNEZ, M. VARGAS-VÁZQUEZ, G. ALEJANDREITURBIDE, G. CASTAÑÓN-NÁJERA, S. HERNÁNDEZ-DELGADO, N. ALMARAZABARCA \& N. MAYEK-PÉREZ. 2016. Marcadores moleculares SCAR para identificar fuentes de resistencia a enfermedades en frijol ayocote (Phaseolus coccineus). PHYTON. Rev Int de Bot Exp. 85: 184-193.

SAGARPA. 2017. Planeación agrícola nacional 20172030: Frijol mexicano. Disponible en https://www. gob.mx/cms/uploads/attachment/file/255625/ Planeaci_n_Agr_cola_Nacional_2017-2030-_parte_ dos.pdf (Consulta 01 de febrero de 2021).

SANGABRIEL, W., R. FERRERA-CERRATO, D. TREJO-AGUILAR, M. MENDOZA-LÓPEZ, J. CRUZ-SÁNCHEZ, C. LÓPEZ-ORTÍZ, J. DELGADILLO-MARTÍNEZ \& A. ALARCÓN. 2006. Tolerancia y capacidad de remediación de combustóleo en el suelo por seis especies vegetales. Rev. Int. Contam. Ambient. 2: 263-73.

SANTALLA, M., J. POWER \& M. DAVEY. 1998. Efficient in vitro shoot regeneration responses of Phaseolus vulgaris and P. coccineus. Euphytica 102: 195-202. https://doi.org/10.1023/A:1018317327302

SANTALLA, M., M. MENÉNDEZ, A. MONTEAGUDO \& A. DE RON. 2004. Genetic diversity of Argentinean common bean and its evolution during domestication. Euphytica 135: 75-87.

https://doi.org/10.1023/B:EUPH.0000009543.46471.72

SCHMIT, V. \& D. DEBOUCK. 1991. Observations of the origin of Phaseolus polyanthus Greenman. Econ. Bot. 45: 345-364. https://doi.org/10.1007/BF02887077

SIAP. 2020. Boletín mensual de producción de frijol, enero 2020. Disponible en: https://www.gob.mx/ cms/uploads/attachment/file/538981/Boletin_ mensual_de_la_produccion_frijol_enero_2020.pdf (Consulta 17 de julio de 2020). 


\section{R. Ruíz-Salazar et al. - El frijol ayocote: recurso genético de México}

SICARD, D., L. NANNI, O. PORFIRI, D. BULFON \& R. PAPA. 2005. Genetic diversity of Phaseolus vulgaris and $P$. coccineus landraces in central Italy. Plant Breed. 124: 464-472.

https://doi.org/10.1111/j.1439-0523.2005.01137.x

SINGH, S., H. TERÁN, S. SCHWARTZ, K. OTTO \& M. LEMA. 2009. Introgressing white mold resistance from Phaseolus species of the secondary gene pool into common bean. Crop Sci. 49: 1629-1637. https://doi.org/10.2135/cropsci2008.08.0508

SINGH, S., H. SCHWARTZ, D. VITERI, H. TERÁN \& K. OTTO. 2014. Introgressing white mold resistance from Phaseolus coccineus PI 439534 to common Pinto bean. Crop Sci. 54: 1026-1032.

https://doi.org/10.2135/cropsci2013.07.0489

SINKOVIC, L., B. PIPAN, E. SINKOVIK \& V. MEGLIC. 2019. Morphological seed characterization of common (Phaseolus vulgaris L.) and runner (Phaseolus coccineus L.) bean germplasm: a Slovenian gene bank example. Biomed. Res. Int. 2019: 6376948. https://doi. org/10.1155/2019/6376948

SPATARO, G., B. TIRANTI, P.ARCALENI, E. BELLUCCI, G. ATTENE, R. PAPA, P. SPAGNOLETTI-ZEULI \& V. NEGRI. 2011. Genetic diversity and structure of a worldwide collection of Phaseolus coccineus L. Theor Appl Genet. 122: 1281-1291. https://doi.org/10.1007/s00122-011-1530-y

TENIENTE-MARTÍNEZ, G., L. GONZÁLEZ-CRUZ, R. CARIÑO-CORTÉS \& A. BERNARDINONICANOR. 2016. Caracterización de las proteínas del frijol ayocote (Phaseolus coccineus L.). Inv. y Des. en Cien. y Tec. de Aliment. 1: 1-6.

VARGAS-VÁZQUEZ, M., J. MURUAGA, J. HERNÁNDEZ \& J. DÍAZ. 2007. Los recursos genéticos vegetales en el INIFAP: estado actual perspectivas y desarrollo. 67 p. Informe de resultados 2007. Instituto Nacional de Investigaciones Agrícolas y Pecuarias, Texcoco, Estado de México.

VARGAS-VÁZQUEZ, M., J. MURUAGA-MARTÍNEZ, S. MARTÍNEZ-VILLARREAL， R. RUÍZSALAZAR, S. HERNÁNDEZ-DELGADO \& N. MAYEK-PÉREZ. 2011. Diversidad morfológica del frijol ayocote del Carso Huasteco de México. Rev. Mex. Biodiv. 82: 767-775.

http://dx.doi.org/10.22201/ib.20078706e.2011.3.698

VARGAS-VÁZQUEZ， M., J. MURUAGAMARTÍNEZ，R. LÉPIZ-ILDEFONSO \& A. PÉREZ-GUERRERO. 2012. La colección INIFAP de frijol ayocote (Phaseolus coccineus L.) I. Distribución geográfica de los sitios de colecta. Rev. Mex. Cien. Agric. 3(6): 1247-1259. https://doi.org/10.29312/remexca.v3i6.1375

VARGAS-VÁZQUEZ, M., J. MURUAGA-MARTÍNEZ \& A. PÉREZ-GUERRERO. 2018. Temperatura y precipitación de los sitios de colecta de variedades nativas de frijol ayocote (Phaseolus coccineus L.). Rev. Mex. Cienc. Agric. 4: 843-853. https://doi.org/10.29312/remexca.v4i6.1153

VITERI, D. \& S. SINGH. 2014. Inheritance of white mold resistance in an Andean common bean A 195 and its relationship with Andean G 122. Crop Sci. 55: 44-49. https://doi.org/10.2135/cropsci2014.02.0145

YU, K., S.J. PARK, AND V. POYSA. 2000. Markerassisted selection of common beans for resistance to common bacterial blight: efficacy and economics. Plant Breed. 119: 411-415. https://doi.org/10.1046/j.1439-0523.2000.00514.x 
